\title{
Performance Assessment System for Energy Efficiency in Wastewater Systems
}

\author{
Catarina Jorge $^{1,2, *(\mathbb{D})}$, Maria do Céu Almeida ${ }^{1}(\mathbb{D})$ and Dídia Covas ${ }^{2}(\mathbb{D}$ \\ 1 Urban Water Unit, National Laboratory for Civil Engineering, LNEC, Av. Brasil 101, \\ 1700-066 Lisbon, Portugal; mcalmeida@lnec.pt \\ 2 CERIS, Instituto Superior Técnico, Universidade de Lisboa, Av. Rovisco Pais, 1049-001 Lisbon, Portugal; \\ didia.covas@tecnico.ulisboa.pt \\ * Correspondence: cnjorge@lnec.pt; Tel.: +351-218443837
}

Citation: Jorge, C.; Almeida, M.d.C.; Covas, D. Performance Assessment System for Energy Efficiency in Wastewater Systems. Water 2021, 13, 1807. https://doi.org/10.3390/ w13131807

Academic Editor: Enedir Ghisi

Received: 1 June 2021

Accepted: 25 June 2021

Published: 29 June 2021

Publisher's Note: MDPI stays neutral with regard to jurisdictional claims in published maps and institutional affiliations.

Copyright: (c) 2021 by the authors. Licensee MDPI, Basel, Switzerland. This article is an open access article distributed under the terms and conditions of the Creative Commons Attribution (CC BY) license (https:// creativecommons.org/licenses/by/ $4.0 /)$.

\begin{abstract}
Performance assessment is essential to effectively evaluate and monitor the activity of water utilities, support decision making, and encourage continuous improvement. Performance assessment systems (PAS), covering several service objectives and criteria, have been successfully applied in water supply and wastewater systems. Tailored approaches focusing on the assessment of the energy use and efficiency in wastewater systems are still limited. This paper aims at the development and demonstration of a comprehensive PAS for energy efficiency, tailored for wastewater systems, incorporating criteria related to energy consumption, operation and maintenance (O\&M) costs, and environmental impacts, such as untreated discharges and greenhouse gases emissions, among others. Management and control of excessive or undue inflows to these systems is specifically addressed by several novel criteria and metrics. The proposed PAS should be adapted by each utility to be aligned with the objectives of the organisation and with the implemented asset management strategy. The proposed approach and the resulting consolidated PAS are thoroughly described. Results from the application of the PAS to several Portuguese utilities are discussed. This PAS aims at contributing to a reliable and replicable process to assess energy efficiency in wastewater systems and to encourage a more rational energy management.
\end{abstract}

Keywords: energy efficiency; performance assessment systems (PAS); performance metrics; undue inflows; wastewater systems

\section{Introduction}

Urban water systems performance is of the utmost importance for responding to current and future challenges in urban areas. In the last decade, performance assessment has been a topic of growing attention in the water industry since water utilities are increasingly incorporating sustainability and improvement principles in their practices, with the water services' regulators as an important driving force [1].

Energy efficiency is a fundamental topic for the water sector [2-5], with implications to water utilities, the users, and the society in terms of economic and financial sustainability and environmental performance. Main environmental issues include the rational and efficient use of natural resources and the reduction of emissions contributing to greenhouse gas (GHG) effects [6,7]. According to [8], the water and wastewater sectors accounted for $3.5 \%$ of electricity use in the EU in 2018, and this share is expected to rise in the short and medium terms. In Portugal, the consumption in the water sector has increased steadily by $10 \%$ over the five-year period from 2011 to 2015 . Despite water supply having a larger share of this consumption (62\% in 2015), wastewater systems have an equally large consumption that cannot be ignored [9]. The referred directive requires the Member States to achieve cumulative end-use energy savings by setting ambitious targets for 2030 and emphasising that "the effective management of water can make a significant contribution to energy savings" [8]. 
In Portugal, the Technical Guide 24 (GT24), published by [9], presents recommendations for efficient energy use in the water sector. The document includes relevant information to the improvement of the energy management of pumping systems and of water and wastewater treatment infrastructures, including recommendations and methodologies for the diagnosis and the monitoring of the energy performance in these assets, among other aspects. The GT24 also introduces the importance of specific water-energy actions, which lead to the improvement of energy efficiency, increase the combined potential of savings, and enhance the competitiveness and resilience of the water-sector systems [9]. This guide and the other mentioned initiatives, together with several water utilities actions that promote energy efficiency in the water sector, also allow contributing to the international commitment of Portugal to reduce GHG emissions [10]. The goal is for the balance between emissions and removals from the atmosphere to be zero by 2050, that is, to have a zero-carbon footprint in water services, achieving carbon neutrality [11].

Most studies on energy use and management in the urban water cycle that have been published in recent years focus on the water supply subsector, with the development of several approaches to foster energy efficiency in water utilities [12-15]. For the wastewater subsector, existing studies are limited and tend to concentrate on individual assets, such as wastewater treatment facilities $[16,17]$ or pumping stations [18,19], with very few existing developments centred on the integrated analysis of energy efficiency in the wastewater system as a whole. A recent study [20] analysed the energy use and efficiency in this subsector integrated in a broad urban water-cycle analysis. For the few specific studies found, none uses a tailored performance assessment system (PAS) to support energy management. There remains a need to adapt and explore new approaches to wastewater and storm water systems to assess particular inefficiencies and opportunities for improvement.

Extensive research and practical applications use structured approaches to define performance assessment systems (PAS) to support the objective and robust management of urban water systems [21-27]. Examples of such systems include those applicable under the regulation activities of water and wastewater services provision and benchmarking activities [28].

Water services are complex due to multiple factors (macroeconomic, social, and environmental); therefore, the use of performance assessment systems are very useful to effectively evaluate and monitor the activity of utilities. More specifically, those benefits are as follows: measuring the quality of service and the utility effectiveness and efficiency; supporting the decision-making process; identifying improvement areas; making the comparison between objectives fair and transparent; providing benchmarking with similar utilities in the country or region or with standards of international good practice; supporting results dissemination; and encouraging utilities to continually improve their service [25-27]. Additionally, the adoption of performance assessment systems can highlight the main inefficiencies in the systems, consequently allowing to set energy efficiency improvement measures (e.g., energy production, energy recovery, single components, and system-wide improvement measures, maintenance measures, among others) that contribute to increase the efficiency of the water-energy infrastructures and its environmental impacts [29-31].

Definition of a PAS is not a trivial task. This definition gains from the alignment with the performance assessment structure proposed by [32-34] for water supply and wastewater systems management. Also, it is of utmost importance to ensure the alignment with PAS for other purposes in the organisations, such as the infrastructure asset management (IAM) methodology proposed by $[35,36]$. The IAM is an integrated approach aligned with the Plan-Do-Check-Act principles typically used in quality systems standards. The PAS should be aligned with the strategic management planning, the strategic objectives of the organisation, and the adopted methodology for implementing asset management. The PAS should take into consideration the organizational resources for effective implementation of a planning process at the tactical level for energy management along with its application in the short to long term. The PAS structure is centred on the definition of objectives, assessment criteria, and metrics (O-C-M) in addition to which it is necessary to define reference values, to allow robust comparisons, and to define targets for each utility [35,36]. 
The objectives aim to consider the several points of view of the assessed problem, and the criteria allow evaluation of several aspects or principles of these objectives. Metrics are parameters or functions used to assess the criteria. The analysis and interpretation of the performance metrics should take into account the context factors, external or internal, considering the area served by each utility. Reference values are standard values used to classify metrics results. Targets are understood as the values to be achieved for each metric for a set deadline. Often, multi-criteria analysis is used to support the selection and prioritization of decisions [37].

The current paper aims to propose and validate a PAS specifically tailored to assess energy efficiency in wastewater systems, taking into consideration the existing methodologies, the common concerns, the long-term objectives on energy efficiency, and the identified knowledge gaps. The main novelties of the proposed approach are a complete objective, criteria, and metrics structure, considering the specificities of each system and the management objectives, taking into account the alignment with previous methodologies developed by the wastewater utilities. Thus, the proposed energy assessment PAS for wastewater systems is a novel approach not yet developed nor applied to real-life wastewater systems and, innovatively, adopts a holistic view of the wastewater system and includes metrics to assess the potential inflows to systems often surcharged by undue or excessive inflows.

\section{Methodology}

\subsection{General Approach}

A methodology for the construction of an oriented PAS for energy efficiency in wastewater systems is described herein. The PAS in the scope of energy efficiency in wastewater systems should be aligned with the strategic objectives of the wastewater utilities since this alignment is one of the main difficulties of utilities [38]. The methodology for the construction of a specific PAS to evaluate energy efficiency in wastewater systems is based on the accepted O-C-M structure of the methodology proposed by $[35,36]$, framed by the typical strategic objectives of the utilities. The focus is on the wastewater-energy use associated with the collection and transport of wastewater throughout the system and also in the current operation and maintenance activities. The system evaluates the energy consumed in pumping stations, the efficiency in the use of resources, the impact of undue inflows in energy consumption, and the organisational and environmental sustainability.

The first step consists of the definition of the objectives by identifying the relevant points of view to assess the performance of wastewater systems in terms of energy efficiency. Once the objectives are set, the second step focuses on the selection of the criteria allowing the evaluation of each objective. The third step is the identification of a set of metrics to assess each criterion. The last step consists of the definition of the reference values and targets (Figure 1). These targets are defined by the wastewater utilities (WU) considering the different planning periods; the definition of targets is out of the scope of the present paper (white box).

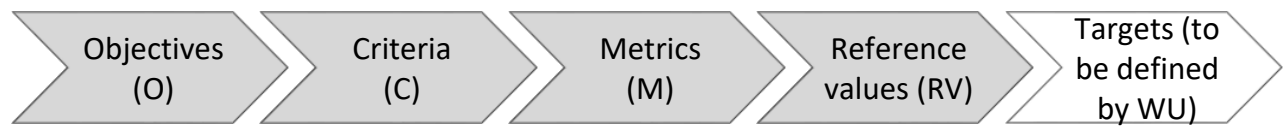

Figure 1. Structure of the PAS.

The adopted approach to develop the PAS is composed of three main stages: (1) PAS development; (2) PAS validation and consolidation; and (3) reference values establishment. This process is schematically depicted in Figure 2, in which grey boxes represent developed tasks and white boxes the respective results. 


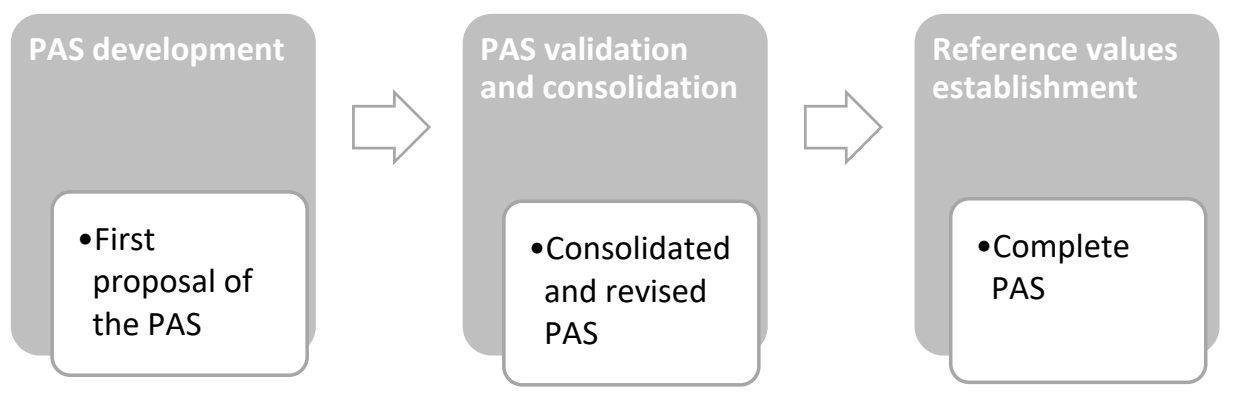

Figure 2. Stages for the construction of the PAS and main results.

The first stage involves the development of a preliminary version of the PAS. The PAS should be as wide as possible to attend to the diversity of wastewater utilities in terms of systems, available data, O\&M practices, etc. Therefore, a validation and consolidation process is applied in a second stage to ensure the adequacy and applicability to typical wastewater utilities.

The definition of reference values (third stage) for general use by wastewater utilities benefits from application to several utilities, and thus, it is recommended to carry out this stage after the consolidation of the O-C-M part of the PAS as the last stage. The application of the consolidated PAS to real systems data provides information to decide on reference values for the metrics, setting the rules to proceed with the assessment of results from the application of the O-C-M. Three classes (good, fair, and poor) are defined to classify the values of the metrics, completing the $\mathrm{O}-\mathrm{C}-\mathrm{M}$ structure. The use of common reference values allows a fairer, transparent, and more systematic assessment of the performance of each wastewater utility as well as the comparison between utilities. Details of these stages and the interaction with Portuguese utilities are described in the following sections. The $\mathrm{O}-\mathrm{C}-\mathrm{M}$ structure and its application are presented in Section 3.

\subsection{PAS Development}

The PAS development stage (stage 1) refers to the development of objectives, criteria, and metrics. This is based on a literature review on the performance assessment systems in the scope of the urban water cycle using standardized metric libraries as well as userdeveloped or customized indicators or indices. Additionally, sessions of brainstorming and debate with wastewater utilities should be promoted together with tailored surveys to their multidisciplinary teams. In the current case, a total of eight wastewater utilities and a total of 21 staff members were invited to the sessions. The face-to-face meetings and brainstorming with the Portuguese wastewater utilities allows ensuring the coherence and feasibility of the methodology as well as the capacity building of the involved utilities. Following this process, research teams from utilities can work together for transferring knowledge, gaining mutual benefits, and enriching the proposed concept.

For the current purpose, the PAS is grounded on the identification of the specific causes and relevance of each identified energy inefficiency for the whole system as well as in sub-catchment areas. The basis for the structure of the approach is the need to ensure the coordination with the existing decision levels and operational areas of the utility as a way to ensure the effectiveness of the actions and a process of continuous improvement, which together with a solutions portfolio, leads to action plans. Utility managers, municipalities, and the local population need to be involved to obtain a broader understanding of problems and to enable the implementation of more effective solutions facilitated by a wider set of actors in what is necessarily a multifaceted problem.

At this level, assuming the utility has adopted a strategy for energy efficiency in wastewater systems, it is necessary to identify the objectives that ensure that the assessment system of the wastewater utility allows to objectively evaluate the magnitude of the problem and the evolution when an action plan is being implemented. Also, current requirements as environmental and utilities sustainability, adaptation, and mitigation to climate change 
and the strategic objectives of utilities should be taken into account to identify the most relevant dimensions to be included in the specific PAS objectives.

In the selection of performance metrics, the following requirements need to be assured for each metric: to be relevant for the objectives of the urban water cycle services; to fit in the predefined assessment criteria; to be clearly defined, with a concise meaning; to be reasonably achievable (which mainly depends on the related variables); to be auditable; to be as universal as possible and to provide a measure which is independent of the particular conditions of the utility; to be simple and easy to understand; and to be quantifiable to provide an objective measurement of the service, avoiding any personal or subjective judgement. Collectively, performance metrics should comply with the following requirements: each metric should provide information significantly different from the other metrics; definitions of the metrics should be unequivocal (this requirement is made extensive to its variables); only metrics which are deemed essential for effective performance evaluation should be established [39].

The leading principles of an integrated assessment focusing on energy efficiency in wastewater systems are based on the adoption of a tailored PAS for energy efficiency in wastewater systems considering not the several energy efficiency aspects in water utilities but the specific ones that focus on water-energy nexus, including dimensions of performance, cost, and risk; diagnosis and evaluation of the problem; the comparability and evaluation of performance over time; the identification of opportunities for increased resource-use efficiency (with focus on energy); the internalisation of a structured process to manage energy efficiency in wastewater systems in coordination with other areas of activity in the utility; and other relevant stakeholders in a continuous improvement process [1].

A validation and consolidation process needs to be posteriorly applied to ensure the adequacy and applicability to typical wastewater utilities.

\subsection{PAS Validation and Consolidation}

Stage 2 consists of the PAS validation and consolidation. The first proposal of PAS, including only objectives, criteria, and metrics, needs to be validated and consolidated with the end-users, the wastewater utilities. For this purpose, the proposed PAS should be analysed together with several wastewater utilities managing different systems (treatment, transport, and collection) with different levels of maturity and resources (human, technological, and economical). The objective is to jointly establish and accept a standard assessment regarding the energy efficiency of wastewater systems to allow comparability and performance assessment over time.

The PAS validation by the utilities provides an opportunity to revise and adjust metrics' definition, to identify relevant sources of information for metrics' calculation, and to test the assessment approach adequacy to different utilities, with different stages of maturity. The validation of the proposed PAS is carried out both with the Portuguese regulator data [28] and for selected wastewater utilities divided into two types: the wastewater bulk transport and treatment utilities (Type A) and the collection and transport (sometimes also include treatment) utilities (Type B). The Portuguese system for services assessment lead by the national regulator is compulsory for all water and waste services providers; therefore, the respective metrics can be calculated, when possible, for all the Portuguese wastewater utilities.

In the current application, eight wastewater utilities representative of the Portuguese reality have supplied additional data for testing the proposed PAS. The followed approach allows ensuring the coherence and feasibility of the methodology as well as capacitating the teams of the involved utilities. This step aims at applying the proposed PAS to each utility reality and consolidating the first version of PAS.

The wastewater utilities (WU) participating in the validation are responsible for urban water systems of different dimensions, with several effective service lodges between 2220 and 296,022, network extensions between $32 \mathrm{~km}$ and $1539 \mathrm{~km}$, number of pumping stations between 2 and 380, and number of wastewater treatment plants (WWTP) between 0 and 
176. Table 1 summarizes the global characterization of the utilities. Data were supplied for the reference period of 2015 to 2019, whenever available.

Table 1. Global characterization of the selected wastewater utilities (WU).

\begin{tabular}{ccccc}
\hline WU/Type & $\begin{array}{c}\text { Number of Effective } \\
\text { Service Lodges }\end{array}$ & Network Extension (km) & Number of Pumping Stations & Number of WWTP \\
\hline WU1/Type A & 35,204 & 32 & 3 & 192 \\
\hline WU2/Type A & 311,490 & 447 & 66 & 65 \\
\hline WU3/Type B & 19,772 & 546 & 380 & 176 \\
\hline WU4/Type A & 488,725 & 1498 & 85 & 16 \\
\hline WU5/Type B & 55,363 & 1539 & 26 & 16 \\
\hline WU6/Type B & 158,303 & 977 & 2 & 17 \\
\hline WU7/Type B & 2220 & 55 & 444 & 1 \\
\hline WU8/Type B & 29,722 & & \\
\hline
\end{tabular}

It should be highlighted that the calculation of metrics requiring more detailed data is globally less feasible in wastewater systems when compared with water-supply systems since the subsector continues to face difficulties regarding information availability and collection. Therefore, only part of the proposed metrics can be currently calculated by most utilities.

\subsection{Reference Values Establishment}

The last stage (stage 3 ) is where the reference values are established. The application of PAS to real systems data provides information to decide on reference values for the metrics, thus setting the rules to proceed with the assessment of results from the application of the objectives, criteria, and metrics.

In the present study, the reference values are defined considering realistic limits for each metric together with a statistical analysis of the metrics application by the utilities. Three classes representative of the quality of service provided (good, fair, and poor) are proposed to classify the values of the metrics. Typically, values of the percentile 25 and percentile 75 are considered when defining the minimum and maximum values of the performance range, respectively. Additionally, the average and median values are analysed. When metrics are obtained with annual and global values, the set of the Portuguese regulator utilities can be considered, which allows a more robust reference-values definition.

Even when only a limited set of values are available, a detailed analysis of the context of each utility should be carried out considering the area served by each wastewater utility. Reference values should always consider the referred context, since the effective operation of systems needs to reflect the proper context and consider adjusted values. Regarding the targets, after analysing their specific PAS with focus on the metrics, each utility has to define, for each metric, reasonable values to be achieved at a different time (short, medium, and long term).

Attending to all the described steps, the resulting consolidated PAS is presented and discussed in the following sections.

\section{Results and Discussion}

\subsection{Consolidated PAS}

The energy-efficiency objectives defined in the proposed PAS are presented below. These consider specifically the water-energy nexus dimensions with focus on the functioning of the wastewater systems considering wastewater pumps, undue inflows, untreated discharges, etc. Therefore, the proposed objectives include the energy-use efficiency, carbon neutrality, and environmental and financial impacts as follows: 
(1) Objective 1-Energy-use efficiency: ensures the efficiency in the use of energy in the operation of the wastewater systems and promote a sustainable use of the resource, targeting the specific inefficiencies of each system. The criteria associated with this objective focus on the adoption of best cleaning, operation, and maintenance practices in the replacement of equipment for more efficient ones or in the implementation of solutions to increase their efficiency and also in the control of undue inflows, among others.

(2) Objective 2-Carbon neutrality: promotes mechanisms to control the emission of GHG associated with energy consumption in wastewater systems, reducing the respective impact in climate change. Encourages fast reductions in GHG caused by the several activities associated with system components that require energy supply. The proposed criteria for this objective focus on replacements at the equipment-, operation-, and maintenance-level actions and promotion of the use of clean energy (such as solar energy, wind energy, and hydropower).

(3) Objective 3-Energy production and recovery: promotes the energy recovery practice and self-energy production in wastewater systems. The criteria associated with this objective relies on energy recovery (e.g., by turbines, Archimedes screw) and energy self-production.

(4) Objective 4-Economical and financial sustainability: ensures efficiency in the use of economic resources associated with energy (e.g., reduce energy costs, energy recovery, equipment, operation, and maintenance).

Each objective should be assessed from different and relevant points of view (criteria). Figure 3 presents the PAS objectives and the corresponding assessment criteria. Each objective has two to three criteria. Specific metrics, preferably quantitative, are defined to obtain an objective assessment of each criterion. The quantitative metrics allow the incorporation and evaluation of objective information, covering a more comprehensive definition of energy efficiency. Metric selection aims to adequately evaluate the proposed criteria, taking into consideration eventual interrelations between metrics.

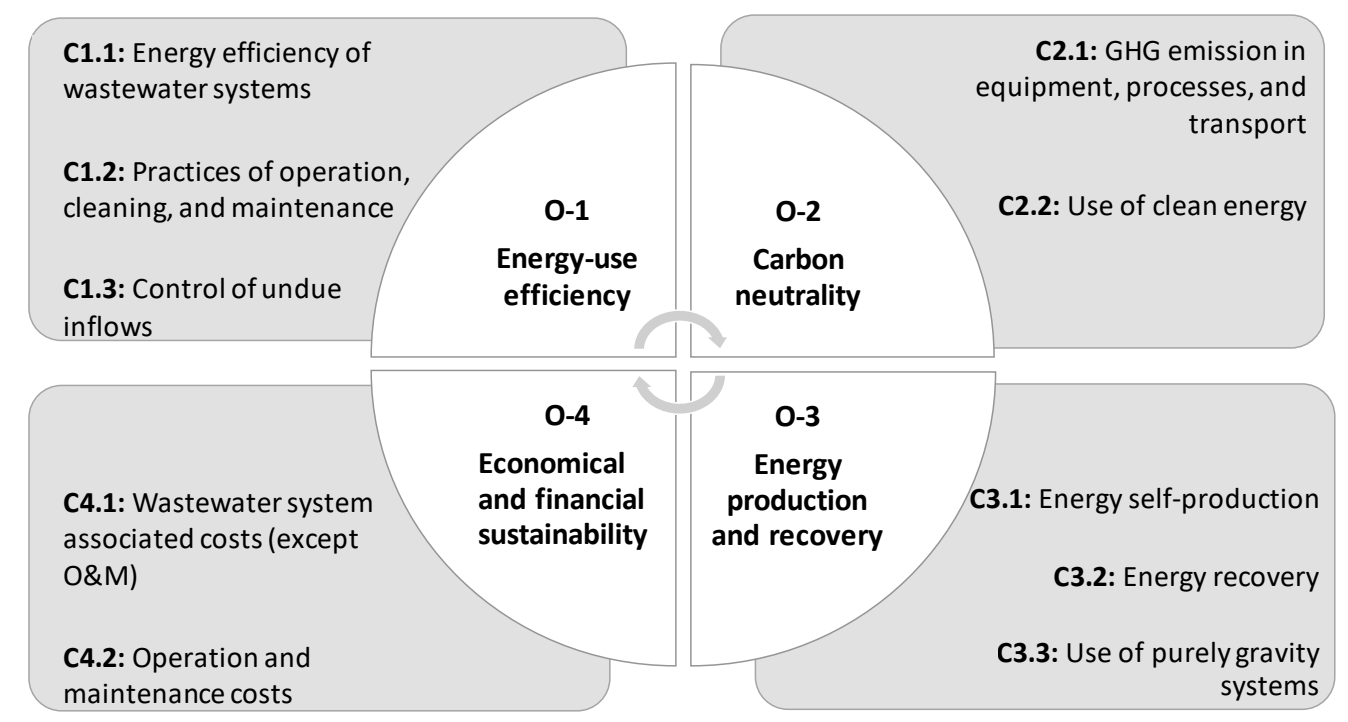

Figure 3. PAS for energy efficiency in wastewater systems objectives and criteria.

The proposed PAS includes 4 objectives, 10 criteria, and 35 metrics, including one metric of the PAS of the Portuguese regulator [28] and 34 new metrics. Objectives, criteria, metrics, and corresponding reference values are presented in Table 2. Since it was not possible to calculate all the metrics due to data availability constraints, only some reference values have been set. The establishment of the remaining reference values will be carried out as a future work. Whenever applicable, a distinction is indicated between the reference 
values for utilities of Type A and Type B. Good performance is highlighted as green, fair performance as yellow, and poor performance as red.

Table 2. Complete PAS: objectives, criteria, metrics, and reference values.

\begin{tabular}{|c|c|}
\hline Metric & Reference values \\
\hline \multicolumn{2}{|c|}{ Objective 1 I Energy-use efficiency } \\
\hline \multicolumn{2}{|c|}{ Criterion 1.1: Energy efficiency of wastewater systems } \\
\hline M1.1.1: Specific energy per total WW volume $\left(\mathrm{kWh} / \mathrm{m}^{3}\right)$ & $\begin{array}{l}\text { A: }[0,0.5] ;] 0.5,0.6] ;] 0.6,+\infty[ \\
\text { B: }[0,0.2] ;] 0.2,0.3] ;[0.3,+\infty[\end{array}$ \\
\hline M1.1.2: Specific energy per total elevated volume $\left(\mathrm{kWh} / \mathrm{m}^{3}\right)$ & $\begin{array}{c}\text { A: }[0,0.5] ;] 0.5,1.7] ;] 1.7,+\infty[ \\
\text { B: }[0,0.09] ;[0.09,0.12] ;] 0.12,+\infty[\end{array}$ \\
\hline M1.1.3: Pumping stations energy efficiency $\left[\mathrm{kWh}\left(\mathrm{m}^{3} .100 \mathrm{~m}\right)\right]-$ metric from [28] & $[0.27,0.45] ;] 0.45,0.68] ;] 0.68,5[$ \\
\hline M1.1.4: Percentage of total energy consumption used for elevation (\%) & $\begin{array}{l}\text { A: }[0,15] ;] 15,30[;[30,100] \\
\text { B: }[0,5] ;] 5,40[;[40,100]\end{array}$ \\
\hline M1.1.5: Percentage of total energy consumption used for WW treatment (\%) & $\begin{array}{l}\text { A: }[0,5] ;] 5,50[;[50,100] \\
\text { B: }[0,5] ;] 5,30[;[30,100]\end{array}$ \\
\hline M1.1.6: Energy consumption for WWTP per population equivalent (kWh/e.p.) & $[0,20] ;] 20,50[;[50,+\infty[$ \\
\hline M1.1.7: Percentage of pumps with acceptable efficiency (\%) & - \\
\hline \multicolumn{2}{|c|}{ Criterion 1.2: Practices of operation, cleaning, and maintenance } \\
\hline M1.2.1: Energy consumption for sewer network cleaning [tep/(100 km.year)] & - \\
\hline M1.2.2: Energy consumption for septic tanks cleaning [tep/(km of travel.year)] & - \\
\hline M1.2.3: Operation practices improvement to lower elevation height (-) & - \\
\hline
\end{tabular}

\section{Criterion 1.3: Control of undue inflows}

$\begin{array}{cc}\text { M1.3.1: Quarter energy peak factor (-) } & {[1.0,1.25[;[1.25,1.75[;[1.75,+\infty[} \\ \text { M1.3.2: Energy consumption seasonality (-) } & {[1.0,1.75[;[1.75,2.5[;[2.5,+\infty[}\end{array}$

M1.3.3: Percentage of energy equivalent to the volume generated in the served area used for elevation (\%)

$[95,100] ;[80,95[;[0,80[$

M1.3.4: Percentage of energy equivalent to the volume generated in the served area used for WW treatment (\%)

$[95,100] ;[80,95[;[0,80[$

M1.3.5: Effect of excessive inflows on energy consumption (\%)

$[0,2.0[;[2.0,5.0[;[5.0,100]$

Objective 2 I Carbon neutrality

Criterion 2.1: GHG emission in equipment, processes, and transport

M2.1.1: Specific GHG emissions associated with total WW volume

$$
\left(\mathrm{kg} \mathrm{CO} 2 \mathrm{eq} / \mathrm{m}^{3}\right)
$$

$[0,0.3] ;] 0.3,0.5] ;] 0.5,+\infty[$

M2.1.2: Specific GHG emissions associated with elevated volume $\left(\mathrm{kg} \mathrm{CO} 2 \mathrm{eq} / \mathrm{m}^{3}\right)$

$[0,0.4] ;] 0.4,0.5] ;] 0.5,+\infty[$

M2.1.3: Specific GHG emissions associated with WW treated volume $\left(\mathrm{kg} \mathrm{CO} 2 \mathrm{eq} / \mathrm{m}^{3}\right)$

$[0,0.2] ;] 0.2,0.4] ;] 0.4,+\infty[$

M2.1.4: Specific GHG emissions associated with the volume generated in the served area $\left(\mathrm{kg} \mathrm{CO} 2 \mathrm{eq} / \mathrm{m}^{3}\right)$

M2.1.5: Specific GHG emissions associated with O\&M $\left.\left.\left.\left(\mathrm{kg} \mathrm{CO}_{2} \mathrm{eq} / \mathrm{m}^{3}\right) \quad\left[0,1 \times 10^{-4}\right] ;\right] 1 \times 10^{-4}, 2 \times 10^{-4}\right] ;\right] 2 \times 10^{-4},+\infty[$ Criterion 2.2: Use of clean energy

M2.2.1: Percentage of total energy consumption from clean energy sources (\%)

\section{Objective 3 I Energy production and recovery}


Table 2. Cont.

\begin{tabular}{|c|c|}
\hline Metric & Reference values \\
\hline M3.1.1: Energy self-production (\%) & {$[20,100] ;[10,20[;[0,10[$} \\
\hline \multicolumn{2}{|l|}{ Criterion 3.2: Energy recovery } \\
\hline M3.2.1: Recovered energy (\%) & - \\
\hline \multicolumn{2}{|c|}{ Criterion 3.3: Use of purely gravity systems } \\
\hline M3.3.1: Percentage of sewer network not associated with pumping stations (\%) & - \\
\hline \multicolumn{2}{|c|}{ Objective 4 I Economical and financial sustainability } \\
\hline \multicolumn{2}{|c|}{ Criterion 4.1: Wastewater system associated costs (except maintenance) } \\
\hline $\begin{array}{l}\text { M4.1.1: Percentage of cost of total energy equivalent to the volume generated } \\
\text { in the served area used for elevation }(\%)\end{array}$ & - \\
\hline $\begin{array}{l}\text { M4.1.2: Percentage of cost of total energy equivalent to the volume generated } \\
\text { in the served area used for WW treatment }(\%)\end{array}$ & - \\
\hline $\begin{array}{l}\text { M4.1.3: Percentage of the cost of total energy consumption used } \\
\text { for elevation }(\%)\end{array}$ & - \\
\hline $\begin{array}{l}\text { M4.1.4: Percentage of the cost of total energy consumption used for WW } \\
\text { treatment }(\%)\end{array}$ & - \\
\hline M4.1.5: Cost associated with the quarter energy peak factor (-) & {$[1,1.5] ;[1.5,2.5[;[2.5,+\infty[$} \\
\hline M4.1.6: Cost associated with energy consumption seasonality (-) & {$[1,2] ;[2,3[;[3,+\infty[$} \\
\hline M4.1.7: Percentage of the cost associated with energy self-production (\%) & - \\
\hline $\begin{array}{c}\text { M4.1.8: O\&M costs of energy consumption reduction by control of } \\
\text { undue inflows }(\%)\end{array}$ & - \\
\hline \multicolumn{2}{|l|}{ Criterion 4.2: Maintenance costs } \\
\hline $\begin{array}{l}\text { M4.2.1: Repair or replacement costs of pumping equipment } \\
\qquad[€ / \text { (equipment.year)] }\end{array}$ & - \\
\hline M4.2.2: Cleaning operations costs of energy [€/(100 km.year $)]$ & - \\
\hline M4.2.3: Solids removal operations costs of energy [€/(kg.year)] & - \\
\hline
\end{tabular}

Due to the high number of proposed metrics, the description and formulation for each one are not detailed herein and are supplied in Appendix A (Table A1).

\subsection{Results from Application to Wastewater Utilities}

Selected metrics were calculated considering two different data sets: data from all the 469 utilities reporting to the Portuguese regulator [28] and data from 8 wastewater utilities directly participating in the application and consolidation of the PAS (Table 1). Not all the proposed metrics could be calculated by the wastewater utilities due to the lack of available data. Due to the number of proposed metrics, only the results of a selected number of metrics, the most relevant, will be presented herein. Metrics requiring global and annual data can generally be calculated for all the Portuguese wastewater utilities. The Portuguese regulator data have been used to support the reference values definition. Metrics requiring more detailed data (e.g., monthly, daily data, audits data) are calculated for the eight involved utilities.

The national water assessment system [28], although designed to provide a national overview of the water and sanitation sector, can contribute to several areas of study with some metrics or variables to support the energy performance assessment. Consequently, one metric associated with energy issues in wastewater systems was selected (M1.1.3: Pumping stations energy efficiency, ERSAR AR10), and other metrics use variables from the Portuguese regulator assessment system (Table A1). 
The set of metrics representative of the global energy efficiency assessment in general wastewater systems are selected and presented herein: Objective 1 -metrics 1.1.1, 1.1.3, 1.1.4, 1.3.1, 1.3.2, and 1.3.3; Objectives 2, 3, and 4-metrics 2.1.1, 3.1.1, and 4.1.5, respectively. Results for the utilities are anonymous and are numerated from 1 to 8 . Results for all the Portuguese wastewater utilities-metrics 1.1.1, 1.1.3, 1.1.4, 2.1.1 and 3.1.1-are marked as ERSAR (orange box and whiskers plot). In all cases, results for the selected utilities are also shown (blue box and whiskers plot). Whenever significant, results are divided between Type A and Type B utilities. The reference period is 2015 to 2019, whenever data are available. Reference values are highlighted with colour bands: good performance is highlighted as green, fair performance as yellow, and poor performance as red.

Figure 4 presents the results obtained for the metric 1.1.3 (pumping stations energy efficiency), which is a metric selected from the Portuguese regulator assessment system [28]. Metric 1.1.3 represents the average amount of energy consumed per cubic meter elevated to a head of $100 \mathrm{~m}$. Reference values range from good performance are marked as green [0.27; 0.45], fair performance marked as yellow ]0.45; 0.68], and finally poor performance marked as red $] 0.68 ; 5[$. The minimum theoretical value corresponds to a $100 \%$ motor and pump performance, and it is $0.27\left(\mathrm{kWh}\left(\mathrm{m}^{3} .100 \mathrm{~m}\right)\right)$. The Portuguese regulator report [28] shows that energy efficiency for wastewater utilities varies between 0.32 and $2.00 \mathrm{kWh} /\left(\mathrm{m}^{3} .100 \mathrm{~m}\right)$. The results show a variation in the quality of service from fair to poor, indicating significant potential for improvement of energy management. For the selected utilities (blue box and whiskers plots), the trend is similar, with an overall performance classified as poor.

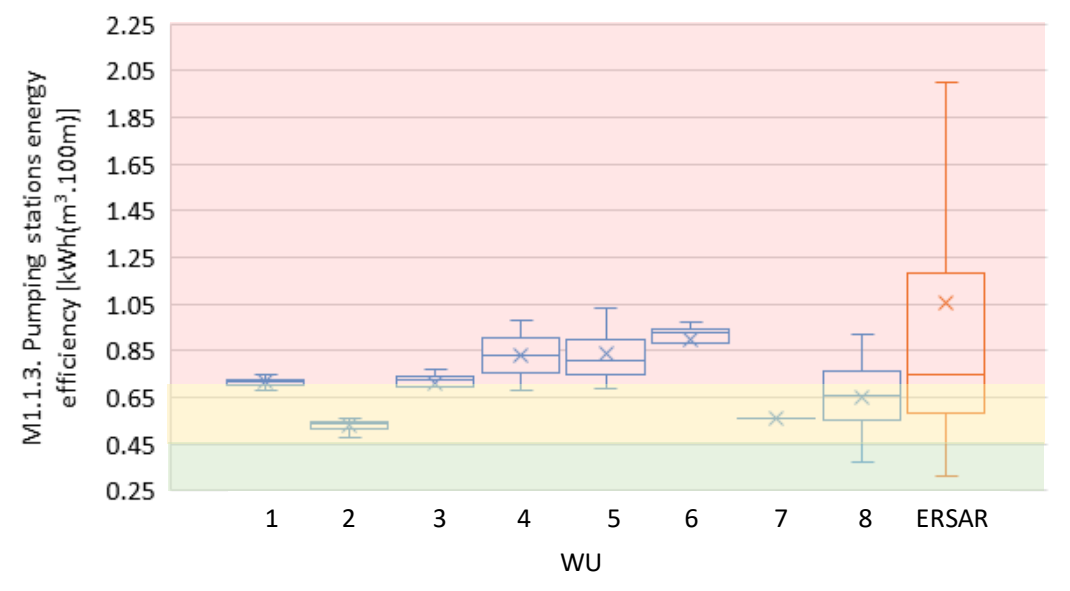

Figure 4. Results for the metric M1.1.3: pumping stations energy efficiency.

Metric 1.1.3 is the key performance indicator AR10, which is the only indicator focusing on energy performance in wastewater systems considered by the Portuguese regulator. Since this indicator is only for pumping stations, it is insufficient to provide guidance regarding the overall energy efficiency of the wastewater systems.

Figure 5 presents the results obtained for the remaining selected metrics for Objective 1. Figure $5 \mathrm{a}, \mathrm{b}$ show that the values for metric 1.1.1 (specific energy) vary significantly from Type A to Type B utilities. Regarding the selected wastewater utilities, the majority of collection and transport (Type B) utilities have values for specific energy below $0.20 \mathrm{kWh} / \mathrm{m}^{3}$ (good performance), whereas Type A utilities values vary between 0.40 and $0.80 \mathrm{kWh} / \mathrm{m}^{3}$ (mainly fair and poor performance). Concerning the universe of the Portuguese utilities, also values from Type B utilities are significantly lower. These results show that Type A consume significantly more than Type B utilities, given the high flow rates that are transported. Additionally, Type A utilities typically have a higher number of pumping stations and WWTP (active energy consumers); therefore, their energy consumption per cubic meter of collected or treated wastewater tends to be higher. 


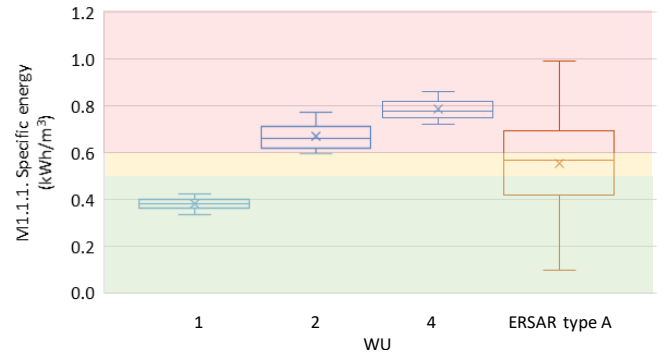

(a)

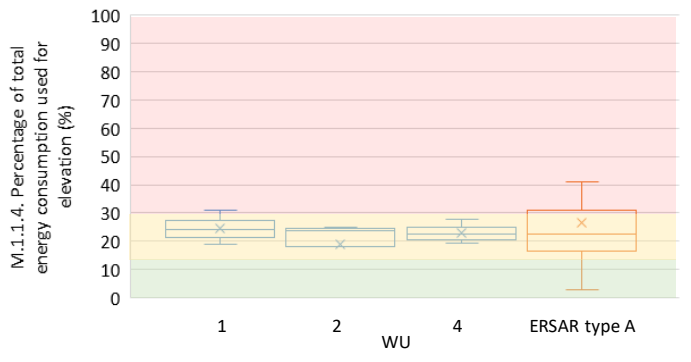

(c)

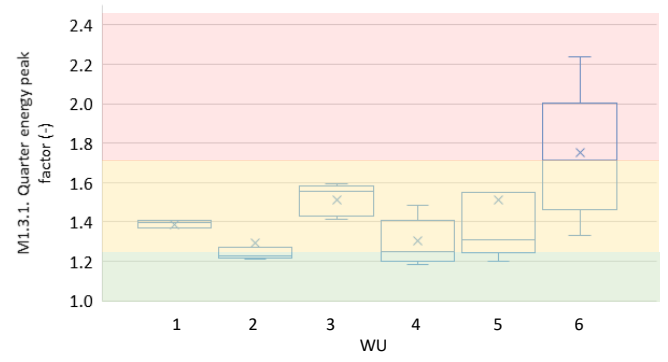

(e)

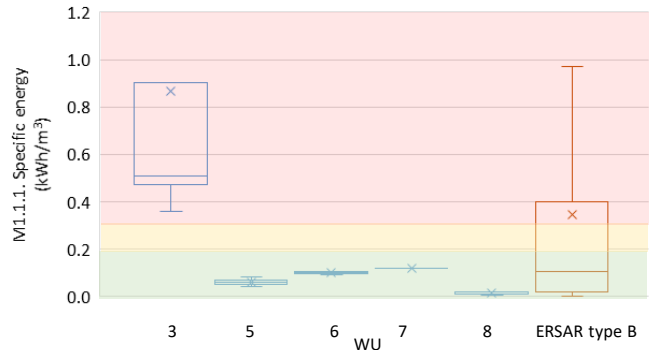

(b)

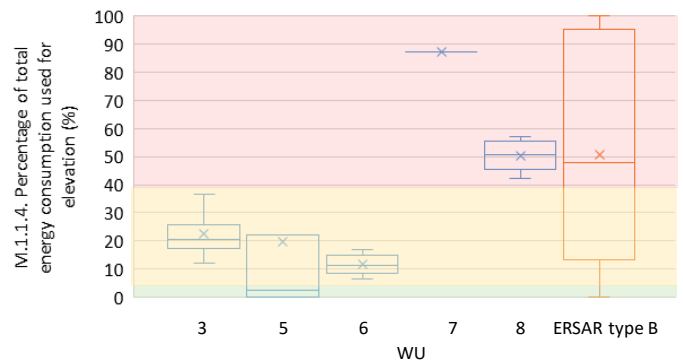

(d)

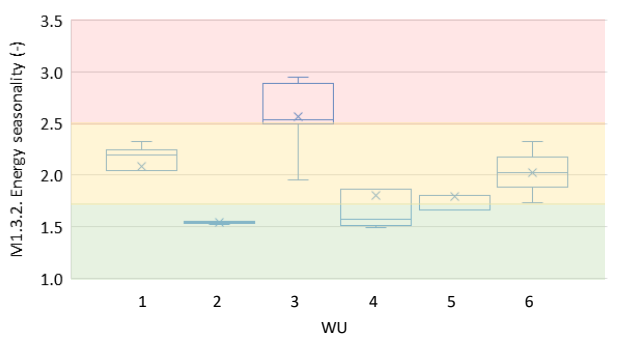

(f)

Figure 5. Results for the selected metrics of Objective 1: (a) M1.1.1 Type A WU; (b) M1.1.1 Type B WU; (c) M1.1.4 Type A WU; (d) M1.1.4 Type B WU; (e) M1.3.1; and (f) M1.3.2.

Regarding the percentage of the total energy used for elevation (metric 1.1.4), Figure $5 c, d$ show that Type B utilities (Figure $5 d$ ) have generally higher values since these utilities commonly have a lower number of WWTP, and the major part of the utility energy consumption is consumed by the pumping stations (despite O\&M energy consumptions). Overall, WU1 has a better performance comparing the Type A wastewater utilities, and WU5 and WU6 also perform better comparing to Type B wastewater utilities.

Metrics 1.3.1 and 1.3.2 (Figure 5e,f) are included in the control of undue inflows criterion (criterion 1.3), and both allow a diagnosis concerning the presence of these type of flows in the network, specifically their impact on energy consumption. Metric 1.3.1 (quarter energy peak factor) represents the ratio between the average three months of higher energy consumption and the average annual consumption. Results for this metric vary from 1.2 and 2.2 over the years for the several utilities, and average values round 1.5 (fair performance). This result shows that, typically, the energy consumption in that specific three months of the year are one and a half times higher when compared to the average annual consumption. This highlights the importance of raising awareness of wastewater utilities to excessive volumes inflowing to the systems, always considering other variables that influence energy consumption (e.g., population, tourism, water supply consumption). WU4, WU5, and WU6 are the ones that have more variable values for this metric over the years. Metric 1.3.2 (energy seasonality) represents the ratio between the average three months of higher energy consumption and the average three months of lower consumption. For the selected utilities, values vary from 1.5 to 3 and WU3, WU4, and WU6 are the ones with more variability along the reference period. 
Finally, metric 1.3 .3 (percentage of energy equivalent to the volume generated in the served area used for elevation) was calculated only by one wastewater utility (WU2) since data requirements include water discharges or calibrated hydraulic model. This metric aims to address the concept of equivalent energy as the total energy required to elevate the total volume generated in the served area if there were no limitations on the transport capacity of the network upstream as well as in the pumping installation. This variable is included in the PAS to calculate the energy that would be consumed additionally if the total volume that left the system (due to discharges or floods) was also elevated. It also intends to raise awareness of wastewater utilities about the effect of acting in control of undue inflows to reduce energy consumption. Expected reduction of energy consumption will only be achieved when the discharged or flooded volumes are eliminated. It also highlights the importance of measuring discharges not only for the well-known reasons associated with environmental impacts. Values for WU2 vary from $99.90 \%$ to $99.99 \%$. Results are not represented in Figure 5 due to the narrow variability of the values.

The proposed reference values for this metric (Table 2) show that almost all the volume generated in the system is elevated, and thus, the control of undue inflows will generate an effective reduction of energy consumption. In all situations, it is important to highlight that the confidence in the results should be evaluated case by case, as the uncertainty associated with data from energy and volume measurements can introduce significant variations. Figure 6 presents the results obtained for the selected metrics for Objectives 2, 3, and 4.

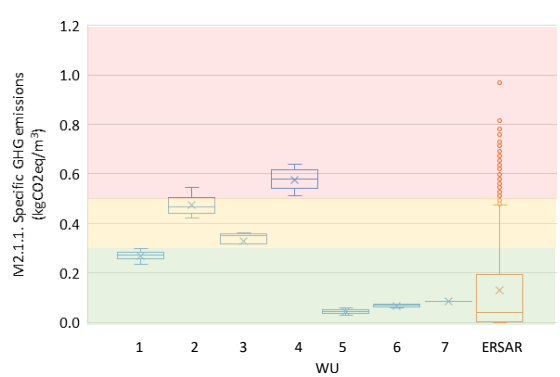

(a)

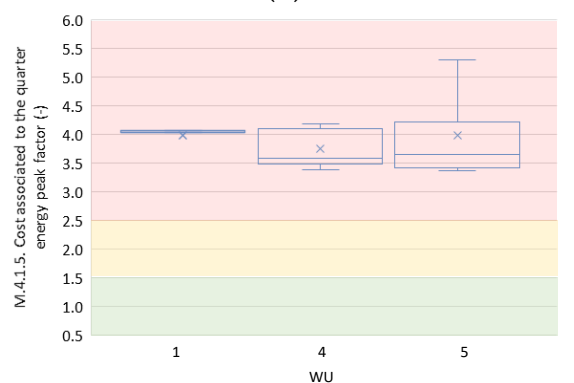

(c)

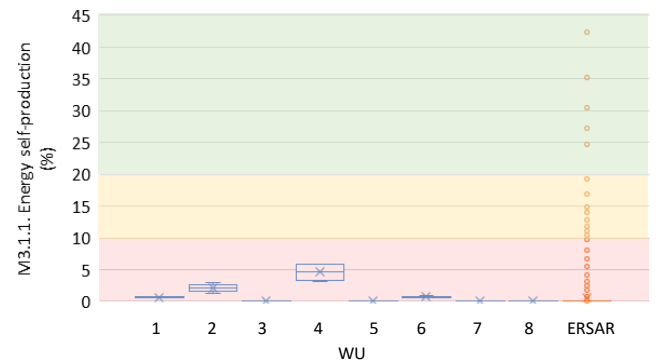

(b)

Figure 6. Results for the selected metrics of Objectives 2, 3, and 4: (a) M2.1.1; (b) M3.1.1; and (c) M4.1.5.

Figure 6a shows that four of the selected wastewater utilities (WU1, WU2, WU3, and WU4) have higher values for the metric 2.1.1 (specific GHG emissions) when compared to all Portuguese utilities (values located on the top of the orange box and whiskers plot) typically associated with the Type A utilities. On the other hand, WU5, WU6, and WU7 have lower values (all Type B wastewater utilities). These results, similar to metric 1.1.1., are explained by the fact that Type A wastewater utilities transport large volumes of wastewater and typically have a higher number of pumping stations and WWTP, which increases their energy consumption per cubic meter of collected or treated wastewater as well as the specific GHG emissions.

Regarding energy self-production (metric 3.1.1. shown in Figure 6b), the values are generally low (for selected WU, all values are above $10 \%$ ), and there is a great opportunity 
for improvement in the energy self-production field using several sources (e.g., solar, wind, hydropower energy). The use of clean energies should be preferable (e.g., solar energy).

Finally, metric 4.1 .5 (Figure 6c) shows the cost associated with the quarter energy peak factor for the utilities that provided costs data for the reference period. This metric is directly related to metric 1.3.1 (Figure 5e) and evidences a very poor performance, with costs associated with the months of higher energy consumption being three or four times higher when compared to the average annual costs.

\subsection{General Recommendations for PAS Application}

The usage of a PAS allows performance assessment through time in the wastewater utility and can also be used for benchmarking between utilities. Globally, data availability and reliability is low in wastewater systems. This lack of data is specially related to the few energy and flow measurements, gaps in inventory data, and few audits of measurement processes, among others. This conditioned knowledge about the systems functioning directly affects the calculation of metrics and the application of the PAS in a comprehensive manner. However, this should be interpreted as an opportunity for utilities to be aware of the data needs and of how much can be gained with better knowledge of the system performance. Overall, data are essential to improve performance and to take adequate decisions, and wastewater utilities need to make a considerable effort regarding data collection, reliability assessment, and processing. For this reason, it is important to identify the multiple uses for data to be collected to ensure that this effort in gathering data is valuable, as the context of each utility must be taken into account.

Regarding each objective and criterion, even if all are significant, when it comes to calculating metrics, each utility should establish priorities and select those that are relevant. The utility can benefit from comparing the results with other similar utilities.

Concerning some general priorities for action that can be applicable to a global set of utilities, there is evidence that Objective 1 is more comprehensive and can easily illustrate the overall performance of the systems. For example, if a utility has a high specific energy (M1.1.1), the percentage of pumps with acceptable efficiency (M1.1.7) should be analysed, and the audits process can be promoted. Also, in this case, it is important to analyse the results of the metrics related to the control of undue inflows (metrics from criterion 1.3).

On the other hand, if a utility is investing in self-energy production (M3.1.1), it is important to analyse the recovered energy (M3.2.1) and the percentage of total energy consumption from clean energy sources (M2.2.1). The latter also affects the metrics of Objective 2 and Criterion 2.1, which are important due to the international agenda and sustainability problems related to GHG emissions and carbon neutrality. Metrics from Objective 4 can be associated with a fourth priority, as this objective does not affect the main energy efficiency issue although it is extremely important in the assessment of the use of economic resources associated with energy. However, each wastewater utility should make this analysis considering their own context.

Finally, the analysis of energy efficiency in wastewater systems using a tailored PAS allows utilities to have a more holistic view of their systems' performance without being conditioned by the regulator performance assessment system, which is intended to be general and to use a limited number of indicators.

\section{Conclusions}

This paper presents a novel performance assessment system for energy efficiency in wastewater systems as well as the results from the validation and application of the PAS involving several Portuguese wastewater utilities willing to tackle this issue.

The main results for some selected metrics allowed assessing performance trends within the utilities and to compare with others. One of the main conclusions is that there is a global deficit of available and reliable data that significantly condition the PAS metrics calculations. However, each utility should consider their own scope and limitations to plan investments in data collection to gather necessary data to enable a proper diagnosis of the 
energy use. The confidence in the results should always be evaluated case by case to avoid the propagation of errors and reduce the associated uncertainty.

The tailored PAS focuses on the overall energy performance of hydraulic systems, allowing to assess the impact of undue inflows on the energy consumption and efficiency of wastewater systems as well as the opportunities to improve practices in operation and maintenance and GHG emissions, among other dimensions.

The application of the methodology was well received by the participating wastewater utilities, and the alignment with the other utilities methodologies was perceived as a significant benefit and presented good results in terms of testing and validation. As future work, it is of utmost importance to apply the proposed methodology to more case studies to proceed with reference-values fine tuning and to propose the remaining reference values. The application of the proposed PAS can be further explored for the selection of energy-efficiency solutions. Finally, it is of the utmost importance to ally the proposed PAS with specific energy balances that support the diagnosis of energy efficiency in wastewater utilities.

Author Contributions: The conceptual idea of this paper was by C.J. and M.d.C.A. Data analysis and investigation were carried out by C.J. Original draft preparation was developed by C.J. The writing, review, and editing were carried out by C.J., M.d.C.A. and D.C. All authors have read and agreed to the published version of the manuscript.

Funding: This research was funded by the Portuguese Foundation for Science and Technology (FCT) through the PhD fellowship PD/BD/135587/2018.

Institutional Review Board Statement: Not applicable.

Informed Consent Statement: Not applicable.

Data Availability Statement: The data presented in this study are contained within the article.

Acknowledgments: The authors gratefully acknowledge the support of FCT, PhD fellowship $\mathrm{PD} / \mathrm{BD} / 135587 / 2018$. The authors thank the following Portuguese utilities for the collaboration in the validation of the PAS, in particular: Águas do Algarve, Águas do Norte, INOVA, Águas da Serra, and SMAS de Sintra.

Conflicts of Interest: The authors declare no conflict of interest.

\section{Appendix A}

Table A1. Complete metrics description and formulation.

\begin{tabular}{|c|c|c|}
\hline Metric & Description & Formulation \\
\hline \multicolumn{3}{|c|}{ Objective 1 I Energy-use efficiency } \\
\hline \multicolumn{3}{|c|}{ Criterion 1.1: Energy efficiency of wastewater systems } \\
\hline $\begin{array}{l}\text { M1.1.1: Specific energy per total WW } \\
\text { volume }\left(\mathrm{kWh} / \mathrm{m}^{3}\right)\end{array}$ & $\begin{array}{l}\text { Energy consumption per unit volume of } \\
\text { collected or treated wastewater. }\end{array}$ & $\begin{array}{l}\text { Total annual energy consumption/total annual } \\
\text { collected or treated wastewater volume. } \\
\text { Note: Variables are included in the Portuguese } \\
\text { regulator annual report. }\end{array}$ \\
\hline $\begin{array}{l}\text { M1.1.2: Specific energy per total elevated } \\
\text { volume }\left(\mathrm{kWh} / \mathrm{m}^{3}\right)\end{array}$ & $\begin{array}{c}\text { Energy consumption per unit volume of } \\
\text { elevated wastewater. }\end{array}$ & $\begin{array}{l}\text { Total annual energy consumption for } \\
\text { elevation/total annual elevated } \\
\text { wastewater volume. } \\
\text { Note: Energy consumption for elevation } \\
\text { included in the Portuguese regulator annual } \\
\text { report. Total annual elevated volume should } \\
\text { be obtained from measurements. }\end{array}$ \\
\hline $\begin{array}{l}\text { M1.1.3: Pumping stations energy efficiency } \\
\qquad\left(\mathrm{kWh} /\left(\mathrm{m}^{3} .100 \mathrm{~m}\right)\right)[28]\end{array}$ & $\begin{array}{l}\text { Average pumping energy consumption in the } \\
\text { system per } 1 \mathrm{~m}^{3} \text { at } 100 \mathrm{~m} \text { of head. }\end{array}$ & $\begin{array}{c}\text { Energy consumption for } \\
\text { elevation/standardization factor. } \\
\text { Note: Standardization factor: } \mathrm{m}^{3} /(\text { year. } 100 \mathrm{~m}) \text {. }\end{array}$ \\
\hline
\end{tabular}


Table A1. Cont.

\begin{tabular}{|c|c|c|}
\hline Metric & Description & Formulation \\
\hline $\begin{array}{l}\text { M1.1.4: Percentage of total energy } \\
\text { consumption used for elevation }(\%)\end{array}$ & $\begin{array}{l}\text { Energy consumption for elevation in relation } \\
\text { to the total energy consumption. }\end{array}$ & $\begin{array}{l}\text { Energy consumption for elevation/total } \\
\text { energy consumption } \times 100 \text {. }\end{array}$ \\
\hline $\begin{array}{l}\text { M1.1.5: Percentage of total energy } \\
\text { consumption used for WW treatment (\%) }\end{array}$ & $\begin{array}{l}\text { Energy consumption for treatment in relation } \\
\text { to the total energy consumption. }\end{array}$ & $\begin{array}{l}\text { Energy consumption for treatment/total } \\
\text { energy consumption } \times 100 \text {. } \\
\text { Note: Energy consumption for treatment } \\
\text { should be obtained from measurements. }\end{array}$ \\
\hline $\begin{array}{l}\text { M1.1.6: Energy consumption for WWTP per } \\
\text { population equivalent (kWh/e.p.) }\end{array}$ & $\begin{array}{l}\text { Energy consumption for treatment per } \\
\text { equivalent of population. }\end{array}$ & $\begin{array}{l}\text { Energy consumption for } \\
\text { treatment/population equivalent. }\end{array}$ \\
\hline $\begin{array}{l}\text { M1.1.7: Percentage of pumps with } \\
\text { acceptable efficiency }(\%)\end{array}$ & $\begin{array}{l}\text { Percentage of pumps with efficiency losses } \\
\text { below } 25 \% \text { of their nominal value. }\end{array}$ & $\begin{array}{l}\text { N. of pumps with efficiency losses below } 25 \% \\
\text { of their nominal value/total } \mathrm{n} \text {. of } \\
\text { pumps } \times 100 \text {. } \\
\text { Note: Requires audits data. }\end{array}$ \\
\hline \multicolumn{3}{|c|}{ Criterion 1.2: Practices of operation, cleaning and maintenance } \\
\hline $\begin{array}{l}\text { M1.2.1: Energy consumption for sewer } \\
\text { network cleaning (tep/(100 km.year }))\end{array}$ & $\begin{array}{l}\text { Annual energy consumption used to clean } \\
\text { each } 100 \mathrm{~km} \text { of the sewer network. }\end{array}$ & $\begin{array}{c}\text { Energy consumption for sewer network } \\
\text { cleaning/number of sewer km. } \\
\text { Note: Energy consumption for sewer network } \\
\text { cleaning should be obtained } \\
\text { from measurements. }\end{array}$ \\
\hline $\begin{array}{l}\text { M1.2.2: Energy consumption for septic tanks } \\
\text { cleaning (tep/(km of travel.year)) }\end{array}$ & $\begin{array}{l}\text { Annual energy consumption used for trucks } \\
\text { per km travelled to empty septic tanks. }\end{array}$ & $\begin{array}{l}\text { Energy consumption of trucks/total } \\
\text { km travelled. }\end{array}$ \\
\hline $\begin{array}{c}\text { M1.2.3: Operation practices improvement to } \\
\text { lower elevation height (-) }\end{array}$ & $\begin{array}{c}\text { Practices implemented at the wastewater } \\
\text { utility to decrease the energy used for } \\
\text { elevation (e.g., pumping operation } \\
\text { levels adjustment). }\end{array}$ & - \\
\hline
\end{tabular}

Criterion 1.3: Control of undue inflows

Ratio between the average monthly consumption in the three months of highest consumption and the average monthly consumption.

Ratio between the average monthly consumption in the three months of highest consumption and the three months of lower consumption.

Total energy required to elevate the total

M1.3.3: Percentage of energy equivalent to the volume generated in the served area used for elevation (\%) were no limitations on the transport capacity of the network upstream of the pumping installation
Average energy consumption in the three months of highest consumption/average monthly energy consumption in the year.

Note: Requires monthly energy consumption measurements.

Average energy consumption in the three months of highest consumption/Average energy consumption in the three months of lowest consumption

Note: Requires monthly energy consumption measurements.

Energy consumption for elevation/energy consumption associated with the total volume generated in the served area $\times 100$.

Note: To obtain the energy consumption associated with the total volume generated in the served area it is necessary to measure the volume discharged or to have hydraulic models available.

M1.3.4: Percentage of energy equivalent to the volume generated in the served area used for WW treatment (\%)

Total energy used to treat the total volume from the served area if there were no limitations on the transport capacity of the network upstream of the pumping installation.
Energy consumption for treatment/energy consumption associated with the total volume generated in the served area $\times 100$.

(Energy associated with the process/total volume of wastewater collected or treated) $x$

(volume of excessive inflows of the dry weather pattern/total volume of wastewater collected or treated) $\times 100$.

Note: To obtain the volume of excessive

inflows it is necessary to have daily flow patterns available. 
Table A1. Cont.

\begin{tabular}{cc}
\hline Metric & Description \\
\hline Objective 2 I Carbon neutrality \\
\hline Criterion 2.1: GHG emission in equipment, processes and transpor
\end{tabular}

Formulation

M2.1.1: Specific GHG emissions associated with total WW volume $\left(\mathrm{kg} \mathrm{CO}_{2} \mathrm{eq} / \mathrm{m}^{3}\right)$

pecific GHG emissions associated with elevated volume $\left(\mathrm{kg} \mathrm{CO}_{2} \mathrm{eq} / \mathrm{m}^{3}\right)$

M2.1.3: Specific GHG emissions associated with WW treated volume $\left(\mathrm{kg} \mathrm{CO} 2 \mathrm{eq} / \mathrm{m}^{3}\right)$

M2.1.4: Specific GHG emissions associated with volume generated in the served area $(\mathrm{kg}$ $\mathrm{CO}_{2} \mathrm{eq} / \mathrm{m}^{3}$ )

\section{M2.1.5: Specific GHG emissions associated with $\mathrm{O} \& \mathrm{M}\left(\mathrm{kg} \mathrm{CO} 2 \mathrm{eq} / \mathrm{m}^{3}\right)$}

Ratio between greenhouse gas emissions associated with the total energy consumption and the volume of wastewater collected or treated.

Total energy consumption $\times 7.04 \times 10^{-4}$

$(*) /$ total volume of wastewater collected or treated $\times 1000$.

Note: $\left.{ }^{*}\right)$ Conversion factor:

https://www.epa.gov/energy/greenhousegas-equivalencies-calculator (accessed on 12 January 2021).

Ratio between greenhouse gas emissions associated with the energy consumption for elevation and the elevated volume.

Ratio between greenhouse gas emissions associated with the energy consumption for treatment and the volume of wastewater collected or treated.

Energy consumption for elevation $\times 7.04 \times 10^{-4}\left({ }^{*}\right) /$ elevated volume $\times 1000$.

Energy consumption for treatment $\times 7.04 \times 10^{-4}\left(^{*}\right) /$ elevated volume $\times 1000$.

Ratio between greenhouse gas emissions associated with the energy consumption associated with the total volume generated in the served area and the volume of wastewater collected or treated.

Energy consumption associated with the total volume generated in the served area $\times 7.04 \times 10^{-4}\left({ }^{*}\right) /$ total volume of wastewater collected or treated $\times 1000$.

Ratio between greenhouse gas emissions associated with the energy consumption for operation and maintenance and the volume of wastewater collected or treated.

Energy consumption for operation and maintenance $\times 7.04 \times 10^{-4}(*) /$ total volume of wastewater collected or treated $\times 1000$.

Criterion 2.2: Use of clean energy

M2.2.1: Percentage of total energy consumption from clean energy sources (\%)
Percentage of total energy consumption that is associated with clean sources (e.g., solar, wind).
Energy consumption from clean sources/total energy consumption $\times 100$.

Note: Energy consumption from clean sources should be obtained from measurements.

\section{Objective 3 I Energy production and recovery}

Criterion 3.1: Self-energy production

Percentage of total energy consumption associated with self-production (e.g., biogas, solar).
Energy consumption from self-production/total energy consumption $\times 100$.

Note: Energy consumption for self-production should be obtained from measurements.

Criterion 3.2: Energy recovery

M3.2.1: Recovered energy (\%)

Percentage of the total energy that is recovered by the wastewater utility.
Energy recovered/total energy consumption $\times 100$.

Note: Energy recovered should be obtained from measurements.

Criterion 3.3: Use of purely gravity systems

Percentage of the total sewer network that is purely gravity.
$\mathrm{Km}$ of purely gravity network/total $\mathrm{km}$ of network.
M3.3.1: Percentage of sewer network not associated with pumping stations (\%)

\section{Objective 4 I Economical and financial sustainability}

Criterion 4.1: Wastewater system associated costs (except maintenance)

M4.1.1: Percentage of cost of total energy equivalent to the volume generated in the served area used for elevation (\%)

M4.1.2: Percentage of cost of total energy equivalent to the volume generated in the served area used for WW treatment (\%)
Cost of total energy required to elevate the total volume generated in the served area if there were no limitations on the transport capacity of the network upstream of the pumping installation.

Cost of total energy required to treat the total volume generated in the served area if there were no limitations on the transport capacity of the network upstream of the pumping installation.
Costs of energy consumption for elevation/costs of energy consumption associated with the total volume generated in the served area $\times 100$.

Costs of energy consumption for treatment/costs of energy consumption associated with the total volume generated in the served area $\times 100$. 
Table A1. Cont.

\begin{tabular}{|c|c|c|}
\hline Metric & Description & Formulation \\
\hline \multicolumn{3}{|c|}{ Objective 2 I Carbon neutrality } \\
\hline \multicolumn{3}{|c|}{ Criterion 2.1: GHG emission in equipment, processes and transport } \\
\hline $\begin{array}{l}\text { M4.1.3: Percentage of the cost of total energy } \\
\text { consumption used for elevation (\%) }\end{array}$ & $\begin{array}{l}\text { Cost of energy consumption for elevation in } \\
\text { relation to the total energy consumption. }\end{array}$ & $\begin{array}{l}\text { Costs of total energy consumption for } \\
\text { elevation / total energy costs } \times 100 \text {. }\end{array}$ \\
\hline $\begin{array}{l}\text { M4.1.4: Percentage of the cost of total energy } \\
\text { consumption used for WW treatment }(\%)\end{array}$ & $\begin{array}{l}\text { Cost of energy consumption for treatment in } \\
\text { relation to the total energy consumption. }\end{array}$ & $\begin{array}{l}\text { Costs of total energy consumption for } \\
\text { treatment / total energy costs } \times 100 \text {. }\end{array}$ \\
\hline $\begin{array}{l}\text { M4.1.5: Cost associated with the quarter } \\
\text { energy peak factor }(-)\end{array}$ & $\begin{array}{l}\text { Ratio of costs with the average monthly } \\
\text { consumption in the three months of highest } \\
\text { consumption and the average monthly } \\
\text { consumption in the year. }\end{array}$ & $\begin{array}{l}\text { Costs of the average energy consumption in } \\
\text { the three months of highest } \\
\text { consumption/costs of the average monthly } \\
\text { energy consumption in the year. }\end{array}$ \\
\hline $\begin{array}{l}\text { M4.1.6: Cost associated with energy } \\
\text { consumption seasonality (-) }\end{array}$ & $\begin{array}{l}\text { Ratio of costs with the average monthly } \\
\text { consumption in the three months of highest } \\
\text { consumption and the three months of } \\
\text { lower consumption. }\end{array}$ & $\begin{array}{l}\text { Costs of the average energy consumption in } \\
\text { the three months of highest } \\
\text { consumption/costs of the average energy } \\
\text { consumption in the three months of lowest } \\
\text { consumption. }\end{array}$ \\
\hline $\begin{array}{l}\text { M4.1.7: Percentage of cost associated with } \\
\text { energy self-production }(\%)\end{array}$ & $\begin{array}{l}\text { Percentage of total energy costs associated } \\
\text { with self-production (e.g., biogas, solar). }\end{array}$ & $\begin{array}{l}\text { Costs of energy consumption from } \\
\text { self-production/total energy costs } \times 100 \text {. }\end{array}$ \\
\hline $\begin{array}{l}\text { M4.1.8: O\&M costs of energy consumption } \\
\text { reduction by control of undue inflows (\%) }\end{array}$ & $\begin{array}{l}\text { Energy costs of operating and maintenance } \\
\text { practices regarding the control of undue } \\
\text { inflows to foster the reduction of } \\
\text { energy consumption. }\end{array}$ & $\begin{array}{l}\text { Energy costs of operating and maintenance } \\
\text { practices regarding the control of undue } \\
\text { inflows / total energy costs } \times 100 \text {. } \\
\text { Note: Energy consumption associated with } \\
\text { operating and maintenance practices } \\
\text { regarding the control of undue inflows should } \\
\text { be obtained from measurements. }\end{array}$ \\
\hline \multicolumn{3}{|c|}{ Criterion 4.2: Maintenance costs } \\
\hline $\begin{array}{c}\text { M4.2.1: Repair or replacement costs of } \\
\text { pumping equipment }(€ / \text { (equipment .year)) }\end{array}$ & $\begin{array}{l}\text { Annual costs associated with the repair or } \\
\text { replacement of pumps and/or } \\
\text { pump components. }\end{array}$ & $\begin{array}{l}\text { Costs associated with the repair or } \\
\text { replacement of pumping equipment/total } \\
\text { number of repaired equipment. }\end{array}$ \\
\hline $\begin{array}{l}\text { M4.2.2: Cleaning operations costs of energy } \\
(€ /(100 \mathrm{~km} \text {.year }))\end{array}$ & $\begin{array}{l}\text { Annual costs associated with cleaning } \\
\text { practices in the sewer network. }\end{array}$ & $\begin{array}{l}\text { Costs of energy associated with cleaning } \\
\text { practices in the sewer network/number of } \\
\text { sewer km. } \\
\text { Note: Energy consumption associated with } \\
\text { cleaning practices should be obtained } \\
\text { from measurements. }\end{array}$ \\
\hline $\begin{array}{l}\text { M4.2.3: Solids removal operations costs of } \\
\text { energy }[€ /(\mathrm{kg} \text {.year })]\end{array}$ & $\begin{array}{l}\text { Annual costs associated with operations } \\
\text { regarding the removal of solids in the } \\
\text { sewer network. }\end{array}$ & $\begin{array}{l}\text { Costs of energy associated with solids removal } \\
\text { operations } / \mathrm{kg} \text { of solids removed. } \\
\text { Note: Energy consumption associated with } \\
\text { solids removal operations should be obtained } \\
\text { from measurements. }\end{array}$ \\
\hline
\end{tabular}

\section{References}

1. Alegre, H.; Almeida, M.C.; Covas, D.; Cardoso, M.A.; Coelho, S.T. Integrated approach for infrastructure asset management of urban water systems. In Proceedings of the International Water Association 4th Leading Edge Conference on Strategic Asset Management, Mülheim an der Ruhr, Germany, 27-30 September 2011.

2. Basupi, I.; Kapelan, Z.; Butler, D. Reducing life-cycle carbon footprint in the (re)design of water distribution systems using water demand management interventions. Urban Water J. 2014, 11, 91-107. [CrossRef]

3. Twomey Sanders, K. The energy trade-offs of adapting to a waterscarce future: Case study of Los Angeles. Int. J. Water Resour. Dev. 2016, 32, 362-378. [CrossRef]

4. Wakeel, M.; Chen, B.; Hayat, T.; Alsaedi, A.; Ahmad, B. Energy consumption for water cycles in different countries: A review. Appl. Energy 2016, 178, 868-885. [CrossRef]

5. Venkatesh, G.; Brattebø, H.; Sægrov, S.; Behzadian, K.; Kapelan, Z. Metabolism-modelling approaches to long-term sustainability assessment of urban water services. Urban Water J. 2017, 14, 11-22. [CrossRef]

6. Nair, S.; George, B.; Malano, H.M.; Arora, M.; Nawarathna, B. Water-energy-greenhouse gas nexus of urban water systems: Review of concepts, state-of-art and methods. Resour. Conserv. Recycl. 2014, 89, 1-10. [CrossRef]

7. Singh, P.; Kansal, A. Energy and GHG accounting for wastewater infrastructure. Resour. Conserv. Recycl. 2018, 128, 499-507. [CrossRef]

8. EP; CEU. Directive (EU) 2018/2002 of the European Parliament and of the Council of 11 December 2018 Amending Directive 2012/27/EU on Energy Efficiency; The European Parliament and the Council of the European Union: Brussels, Belgium, 2018. 
9. ERSAR; ADENE. Efficient Energy Uses in Water Services. Technical Guide 24; The Water and Waste Services Regulation Authority (ERSAR) and Agency for Energy (ADENE): Lisbon, Portugal, 2018; Available online: http://www.ersar.pt/pt/publicacoes/ publicacoes-tecnicas / guias (accessed on 15 January 2021)(In Portuguese). ISBN 978-972-98996-5-2.

10. Turner, D.A.; Williams, I.D.; Kemp, S. Greenhouse gas emission factors for recycling of source-segregated waste materials. Resour. Conserv. Recycl. 2015, 105, 186-197. [CrossRef]

11. RNC: Roadmap for Carbon Neutrality (2050). Long-Term Strategy for Carbon Neutrality of the Portuguese Economy by 2050. Available online: https:/ / descarbonizar2050.apambiente.pt/ (accessed on 12 January 2021).

12. Duarte, P.; Alegre, H.; Covas, D. Avaliação do desempenho energético em sistemas de abastecimento de água. In Proceedings of the VIII Seminário Ibero-Americano SEREA 2008, Lisbon, Portugal, 16-19 July 2008. (In Portuguese).

13. Cabrera, E.; Pardo, M.A.; Cobacho, R.; Cabrera, E., Jr. Energy audit of water networks. J. Water Resour. Plan. Manag. 2010, 136, 669-677. [CrossRef]

14. Mamade, A.; Loureiro, D.; Alegre, H.; Covas, D. A comprehensive and well tested energy balance for water supply systems. Urban Water J. 2017, 14, 853-861. [CrossRef]

15. Mamade, A.; Loureiro, D.; Alegre, H.; Covas, D. Top-Down and Bottom-Up Approaches for Water-Energy Balance in Portuguese Supply Systems. Water 2018, 10, 577. [CrossRef]

16. Nowak, O.; Enderle, P.; Varbanov, P. Ways to optimize the energy balance of municipal wastewater systems: Lessons learned from Austrian applications. J. Clean. Prod. 2015, 88, 125-131. [CrossRef]

17. Silva, C.; Quadros, S.; Ramalho, P.; Alegre, H.; Rosa, M.J. Translating removal efficiencies into operational performance indices of wastewater treatment plants. Water Res. 2016, 57, 202-214. [CrossRef] [PubMed]

18. Hou, S.; Li, D.; Xi, Y.; Cen, L. Energy-saving optimization of urban drainage system based on pump performance. In Proceedings of the 27th Chinese Control and Decision Conference, 2015 (2015 CCDC), Qingdao, China, 23-25 May 2015 ; pp. 308-313.

19. Zhang, Z.; Kusiak, A.; Zeng, Y.; Wei, X. Modelling and optimization of a wastewater pumping system with data-mining methods. Appl. Energy 2016, 164, 303-311. [CrossRef]

20. Loureiro, D.; Silva, C.; Cardoso, M.A.; Mamade, A.; Alegre, H.; Rosa, M.J. The Development of a Framework for Assessing the Energy Efficiency in Urban Water Systems and Its Demonstration in the Portuguese Water Sector. Water 2020, 12, 134. [CrossRef]

21. Cardoso, M.A.; Coelho, S.T.; Matos, R.; Alegre, H. Performance assessment of water supply and wastewater systems. Urban Water J. 2004, 1, 55-67. [CrossRef]

22. Cabrera, E.; Pardo, M.A. (Eds.) Performance Assessment of Urban Infrastructure Services: Drinking Water, Wastewater and Solid Waste; IWA Publishing: London, UK, 2008; ISBN 9781843391913.

23. Cardoso, M.A. Performance Assessment of Urban Drainage Systems. Ph.D. Thesis, Instituto Superior Técnico, Lisbon, Portugal, 2008. (In Portuguese).

24. Canneva, G.; Guérin-Schneider, L. National monitoring of water utility performance in France. Water Sci. Technol. Water Supply 2011, 6, 745-753. [CrossRef]

25. Van Den Berg, C.; Danilenko, A. The IBNET Water Supply and Sanitation Performance Blue Book 2011: The International Benchmarking Network for Water and Sanitation Utilities Databook; The World Bank: Washington, DC, USA, 2011. [CrossRef]

26. Vilanova, M.R.N.; Filho, P.M.; Balestieri, J.A.P. Performance measurement and indicators for water supply management: Review and international cases. Renew. Sustain. Energy Rev. 2015, 43, 1-12. [CrossRef]

27. Alegre, H.; Baptista, J.M.; Cabrera, E., Jr.; Cubillo, F.; Duarte, P.; Hirner, W.; Merkel, W.; Parena, R. Performance Indicators for Water Supply Services, 3rd ed.; Manual of Best Practice Series; IWA Publishing: London, UK, 2016; ISBN 978-178-0406-32-9.

28. ERSAR. Annual Report on Water and Waste Services in Portugal (RASARP); ERSAR: Lisbon, Portugal, 2018; Volume 1. Available online: http://www.ersar.pt/pt/publicacoes/relatorio-anual-do-setor (accessed on 15 January 2021)(In Portuguese). ISBN 978-989-8360-36-6.

29. Puleo, V.; Notaro, V.; Freni, G.; La Loggia, G. Water and energy saving in urban water systems: The ALADIN project. Procedia Eng. 2016, 162, 396-402. [CrossRef]

30. Liu, F.; Ouedraogo, A.; Manghee, S.; Danilenko, A. A Primer on Energy Efficiency for Municipal Water and Wastewater Utilities. In Energy Sector Management Assistance Program; Technical Report 001/12; World Bank: Washington, DC, USA, 2012.

31. Berger, V.; Niemann, A.; Frehmann, T.; Brockmann, H. Advanced energy recovery strategies for wastewater treatment plants and sewer systems using small hydropower. Water Util. J. 2013, 5, 15-24.

32. ISO. Activities Relating to Drinking Water and Wastewater Services—Guidelines for the Assessment and for the Improvement of the Service to Users; ISO 24510; International Organization for Standardization: Geneva, Switzerland, 2007.

33. ISO. Activities Relating to Drinking Water and Wastewater Services-Guidelines for the Management of Wastewater Utilities and for the Assessment of Drinking Water Services; ISO 24511; International Organization for Standardization: Geneva, Switzerland, 2007.

34. ISO. Service Activities Relating to Drinking Water and Wastewater-Guidelines for the Management of Drinking Water Utilities and for the Assessment of Drinking Water Services; ISO 24512; International Organization for Standardization: Geneva, Switzerland, 2007.

35. Almeida, M.C.; Cardoso, M.A. Infrastructure Asset Management of Wastewater and Rainwater Services. Technical Guide n.17; ERSAR, LNEC, IST: Lisbon, Portugal, 2010; (In Portuguese). ISBN 978-989-8360-05-2.

36. Alegre, H.; Covas, D. Infrastructure Asset Management of Water Services. Technical Guide, n.16; ERSAR, LNEC, IST: Lisbon, Portugal, 2010; (In Portuguese). ISBN 978-989-8360-04-5. 
37. Carriço, N.; Covas, D.; Almeida, M.C. Multi-criteria decision analysis in urban water asset management. Urban Water J. 2021 , 1-12. [CrossRef]

38. Almeida, M.C.; Brito, R.S.; Cardoso, M.A.; Beceiro, P.; Jorge, C.; Technical Course, N. Approach to Assess and Control Inflows into Sewers; Technical Course N. 8; ERSAR: Lisbon, Portugal, 2018; ISBN 978-972-98996-8-3.

39. Alegre, H.; Covas, D.; Almeida, M.C. Integrated Planning of Urban Water Services: A Global Approach; TRUST Manual of Best Practice; LNEC and IST: Lisbon, Portugal, 2015; Volume 1. 